\title{
Policy implementation considerations for basic services: A South African urban sanitation case
}

\author{
L Taing $^{1 *}$ \\ ${ }^{1} / \mathrm{HE}$-Delft Institute for Water Education, Sanitary Engineering Research Group, Delft, The Netherlands
}

\begin{abstract}
The Republic of South Africa formulated numerous progressive laws, regulations and strategies from 1994 to 2008 to support the provision of free basic sanitation access to the poor by 2014. The State has yet to achieve this objective in urban areas ostensibly due to the poor municipal execution of national policy. This paper challenges this viewpoint, as it ignores policy weaknesses and overlooks the influence of non-municipal actors in service delivery. An assessment of national policy and implementation in South Africa's second largest city (Cape Town) indicated that irreconcilable differences between municipal officials, residents and advocates' interpretations of broadly-framed national policy, as well as policy gaps specific to servicing informal settlements and providing shared sanitation, contributed to the municipality's failure to achieve policy objectives. The actors' differences and policy shortcomings necessitated municipal policy reformulation according to the 'lived' and 'practical' realities of servicing informal settlements. The findings suggest a disproportionate focus on turning national policy into practice - for this viewpoint misses how local actors' perspectives and current practices can shape policy. Understanding, accepting and addressing the interplay between policymaking and implementation can contribute to more constructive means of effectively delivering sanitation in South Africa.
\end{abstract}

Keywords: lifeline tariffs, implementation science, public policy and administration, shared sanitation, informal settlements, service provision

\section{INTRODUCTION}

Sanitation is commonly considered taboo to discuss in public. This private matter, however, was at the centre of a national South African debate after newspapers splashed photographs of municipality-built toilets without walls across their front pages in the run-up to the 2010 FIFA World Cup. The photographs upset many people, who were appalled that a brand-new football stadium was built with public money while people defecated in full view just $65 \mathrm{~km}$ away in a low-income Cape Town suburb.

The open-toilet scandal provoked public introspection about the urban poor's inability to defecate with dignity after a quarter century of democratic rule. Municipal provision of non-sewered container-based toilets in informal settlements especially evoked concerns about post-Apartheid progress. Representatives of different arms of national government and social advocates quoted legislation and policy to fault the municipality for not complying with countrywide norms and basic standards (MSTT, 2012; SAHRC, 2014). Put simply, critics had no doubt that the municipality had disregarded national policy.

The focus on municipal shortcomings reflects the prevailing notion of poor policy implementation being the primary reason South Africa has thus far failed to achieve its urban sanitation objectives. This paper challenges this simple explanation because wholly faulting municipal implementation depends on the assumption of there being a workable national policy. It also ignores how a diverse range of actors and factors can affect policy processes.

This paper details how local contestation has influenced the design and delivery of sanitation policies and services for informal settlements in South Africa's second-largest

\section{${ }^{*}$ Corresponding author, email: lina.taing@unu.edu}

Current affiliation: United Nations University Institute for Water, Environment and Health (UNU-INWEH), Water and Health, Hamilton, Ontario, Canada Received 2 January 2018; accepted in revised form 20 September 2019 metropolitan area. After describing the methods and analytical framing (implementation studies) employed, the paper summarises the key principles underpinning South Africa's sanitation policy. It thereafter discusses policy implementation over a 14-year period in the City of Cape Town (CoCT) Municipality. Based on the way people create policy, deliver services, and use toilets, it suggests that policy gaps and rival understandings of ambiguous policy language necessitated the reformulation of national policy according to local contexts. The author hence argues that there is a disproportionate focus on turning national policy into practice -for this viewpoint misses how local contexts can reshape and redefine policy. This case illustrates the need to consider implementation factors to realise servicing policy objectives.

\section{METHODS}

This paper is based on doctoral research that built on two Water Research Commission (WRC) studies on sanitation for South African informal settlements (Taing et al., 2013, 2014). The studies considered different stages of policy implementation and service provision - ranging from infrastructure planning to maintenance - from the viewpoints of municipal officials and residents. To consider whether policy had changed during implementation following the conclusion of the studies, the author additionally compared policy implementation data to national sanitation guidance for informal settlements. The next sections detail the means of data collection and analysis.

\section{Data collection}

The author collected 3 types of data (secondary, interview and observational) following a mixed method for multiphase longitudinal studies. Secondary data was based on a desktop review of available documents concerning the design, implementation and regulation of sanitation for the urban poor from 1994 to 2014 (e.g., policies, project files, media statements, 
print articles and literature). The author interviewed 4 national policymakers in April 2015, and conducted semi-structured interviews with residents, municipal officials, activists and academics involved in policy design, implementation and advocacy from March 2010 to August 2013.

The author also collected data as a participant observer in three CoCT offices for 9 months from March 2010 to September 2012, and at an ablution block in BM Section informal settlement from November 2012 to August 2013. At CoCT, she joined municipal officials as an intern in the informal settlement units of the Water and Sanitation Department and Human Settlements (then Housing) Directorate. This entailed shadowing officials when they attended meetings and visiting sites to install or manage toilets and supporting inter-departmental sanitation projects. At BM's ablution block, she assisted janitors while observing how users interacted with the facilities before and after cleaning. She lastly observed and interacted with janitors of flush toilets interspersed throughout the settlement.

The University of Cape Town (UCT) conferred ethical approval, and $\mathrm{CoCT}$ officials and community leadership granted permission to undertake research in their areas of jurisdiction. Aside from policymakers with public profiles, the author does not use personal identifiers in order to protect participants' anonymity.

\section{Data analysis}

The paper's focus is to unpack a little-explored topic in South Africa: considerations of national informal settlements sanitation policy from an implementation perspective. It does not detail specific informal settlement case data, as this has been summarised in two WRC reports and two other journal publications (Taing, 2017a, 2017b). The paper instead discusses key research findings in its application of an implementation studies analytical framework, which complements and challenges the policy cycle framing dominant in South African policymaking.

\section{Policy cycle framing}

Lasswell's (1956) policy cycle framework characterises policymaking as 5 sequential stages: agenda setting, policy formulation, decision-making, implementation and evaluation stages. This framing has been so popular in policy studies that Hill and Hupe (2010) described it as the 'textbook approach'.

The notion of policy occurring in stages is ingrained in South African government structures and processes (DPLG, 2007; RSA, 1998, 2000). Influential sanitation figures adopting this linear view of policymaking tend to attribute policy failure to implementers who supposedly are either non-compliant with or have maladministered and misinterpreted national legislation and policy (DHS, 2012; DWA, 2013; DWAF, 2004; Mjoli et al., 2009; MSTT, 2012; SAHRC, 2014; SJC, 2013). South Africa's policy cycle preoccupation has resulted in very little deliberation of possible shortcomings in policy.

Critics of the policy cycle, however, note that the framework adopts a top-down perspective in assuming that good policies often fail due to bad implementation and oversimplifies policymaking (Hill and Hupe, 2010). Additionally, the policy cycle assumes that policymaking is sequential, which overlooks potential disruption and feedback that can change policy processes. Sabatier (2007), for example, noted that it neglects how policies can change during implementation and following evaluation. The next section details an analytical framing that counters this predominant framework.

\section{Policy implementation framing}

Policy implementation studies evolved to address the cycle framework's shortcomings. Policy implementation framing focuses on if and how an objective is realised. Its key assumptions are that: (i) policies are workable; (ii) analysis considers how change occurs and how it is induced; (iii) implementation is complicated due to the diverse range of variables effecting sometimes unpredictable changes; and (iv) implementation dominates outcomes, for implementers ultimately are responsible for balancing political pressure and sourcing resources to realise change.

This paper's analysis uses a policy implementation framing to complement and challenge South Africa's prevailing policy cycle rationale. Specifically, an adaptation of Mazmanian and Sabatier's (1989) 21-variable framework for analysing technologically oriented policy was applied (Fig. 1). Unlike other implementation theorists, Mazmanian and Sabatier included technical variables in their framework, which is significant for this research because sanitation delivery involves technological systems and knowledge.

The author, however, restructured and re-categorised Mazmanian and Sabatier's framework for analysis because of her intent to assess the interplay between actors' perspectives and sanitation outcomes rather than influence policy processes. Mazmanian and Sabatier designed their framework to help elected officials shape implementation. Sabatier (1986) admitted that this intent indicated they had a legalistic and top-down bias. Given that the author intended to understand factors and interactions between variables (Hill and Hupe, 2010: 49) rather than control processes, the author restructured the framework

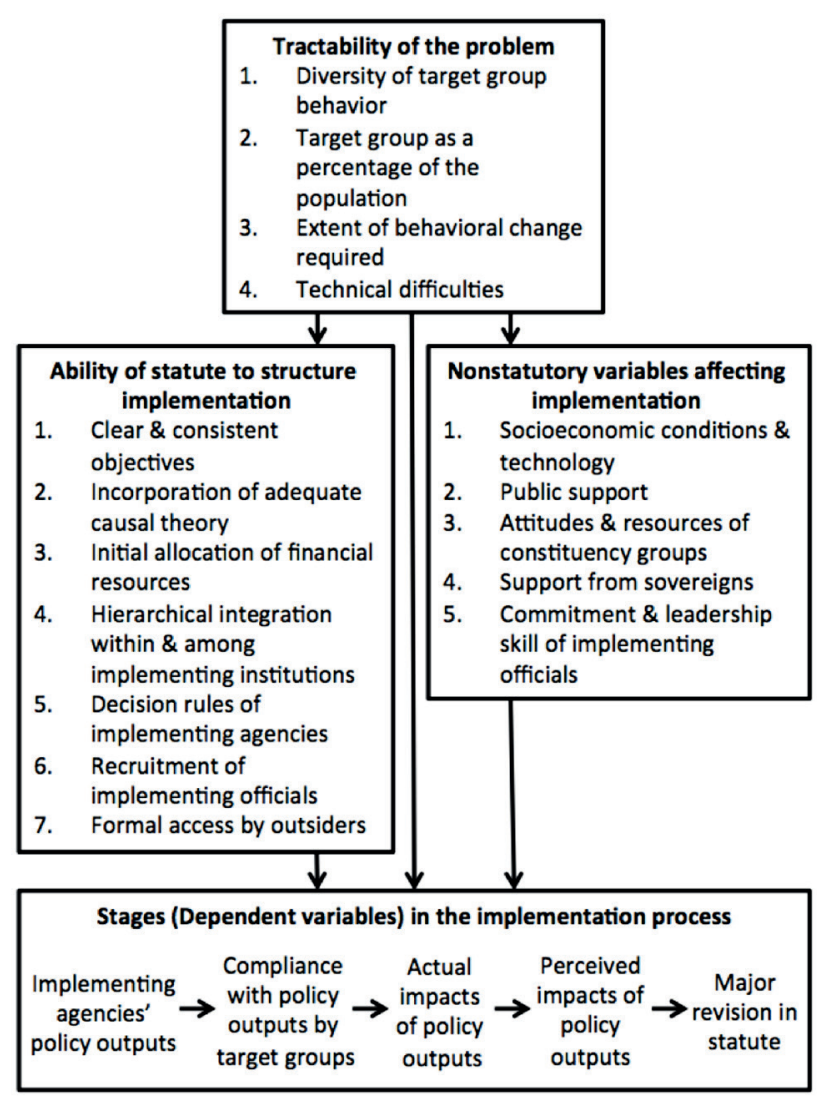

Figure 1. Mazmanian and Sabatier's (1989, p. 22) framework 
and regrouped variables according to a pared understanding of policy processes (i.e. targeting; policy-implementation process; and evaluation).

Furthermore, the author consolidated Mazmanian and Sabatier's variables and simplified their language. Mazmanian and Sabatier had multiple variables addressing themes from different viewpoints, which made the framework's structure clunky and repetitive. Their language was also unnecessarily complex (DeLeon, 1999) they note that in many ways, the implementation and evaluation stages are one and the same (although necessarily separated for reasons of functional effectiveness. The author merged the actorrelated variables by themes and substituted terms with those used in contemporary policy studies to facilitate viewpoint comparisons, reduce repetition and make the framework more user-friendly.

Lastly, the author expanded the actor categories, as Mazmanian and Sabatier's three perspectives (policymaker, implementer and target group) excluded various arms of government and external actors. A generic actor list based on purpose - i.e., policymaker (agenda-setter, formulator or decision-maker); implementer; beneficiary (recipient) or evaluator and regulator (enforcer) - was devised. The adapted analytical framework is depicted in Fig. 2.

What follows is an application of the adapted framework that firstly summarises the development of South Africa's sanitation policy from 1994. The paper then presents data by linking policy to practice in detailing CoCT's informal settlement programming from 2001 to 2014 . The research findings are lastly discussed in the evaluation section, which outlines said municipality's progress after two decades of democracy.

Policy-implementation process

5. Valid assumptions

6. Clear objectives

7. Financial allotment

8. Implementers' capability

9. Extent of (de)centralisation

- Decision-making

- Participatory processes

- Veto \& clearance points

1. Problem identification

2. Targeted changes

3. Actors' specification

4. Technical aspects

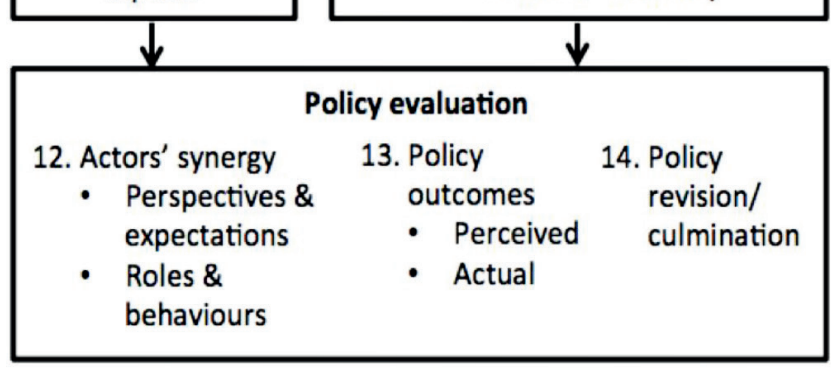

Figure 2. Adapted analytical framework

\section{South African sanitation policy}

South Africa's government disseminated numerous sanitationrelevant laws, strategies and regulations from 1994 to 2008 (DWAF, 1994, 2001, 2003, 2008; RSA, 1994, 1996a, 1997). A common objective underpinning national policy was the need to progressively improve conditions of households that had been disadvantaged by colonial and apartheid policies. Democratic policymakers thus embedded the right to live in an environment that did not harm one's health or well-being, as well as rights to water and having one's dignity respected and protected, in the Constitution (RSA, 1996a). These rights collectively are understood as the right to basic sanitation access, which subsequent legislation explicitly guaranteed (RSA, 1997).

Initially, policymakers endeavoured to realise this objective through housing provision: by 2000, one million houses had been built (Huchzermeyer, 2001). National government moreover installed new rural bulk water infrastructure, and subsidised low-income households' recurrent costs. Despite this infrastructure drive, 1 in 7 households lacked toilet access at the turn of the century (Stats SA, 2001). Available data indicated to policymakers that extreme poverty significantly constrained access in spite of municipalities offering even highly-subsidised tariffs (Kasrils, 2001; Muller, 2008). This analysis triggered the policy decision to shift from an economically-driven policy (centred on consumer cost recovery), to a lifeline tariff social policy in which the government fully-subsidised basic water and sanitation services for the poor. This policy decision, coupled with local election campaign promises (Mosdell, 2006), culminated in the national government's broadened pledge of providing poor households with a basic package of limited water, sanitation, refuse removal and electricity services at no cost in January 2001.

While Free Basic Services (FBS) conflicts with the paymentfor-services rationale, South Africans have come to regard it as a necessary equity instrument. Policymakers had not intended to foster sentiments of entitlement or dependability, as they highlighted that the 'right comes with a responsibility-not to abuse the right to free basic services and to pay for services where these are provided over and above a basic service' (DWAF, 2003 p. ii). Such language is reminiscent of the democracy's preceding self-help policy, in which indigents were to progressively improve living conditions by joining capital subsidies with their own resources (DWAF, 1994; Wilkinson, 1998).

The free water and sanitation components went into effect in June 2001 (Muller, 2008). Considering best urban practices across the country, national policymakers zeroed in on Durban's 1996 Free Basic Water (FBW) cross-subsidy, which Kasrils (2001 p. 53) noted had demonstrated that it was feasible to have consumers in formal areas fully subsidise the urban poor's consumption. Encouraged by Durban's success, national policymakers concluded that municipalities could offset their FBS costs with revenue. The poor hence were to equitably benefit from this unprecedented servicing policy, regardless of where they lived.

Notably, while Durban's FBW cross-subsidy informed water policy design, policymakers did not have a comparable policy example for the conceptualisation of Free Basic Sanitation (FBSan). Additionally, policymakers did not acknowledge how the government's then position of eradicating informal settlements (in 2000/01) affected implementation. (National housing policymakers later recognised the need and opportunities for informal settlement upgrading in 2004 
(DoH, 2004)). The significance of these points is revisited in the paper's discussion section.

After a decade of policymaking, national policymakers stated from thenceforward they would support and regulate services implemented by newly-established municipalities, which were supposedly ready to 'assume full responsibility' for service delivery in the democracy's second decade:

We are now entering another important phase in the long process of building local democracy. We have established our new municipalities. Now we have to make sure they do their job of providing services to our people, efficiently, effectively, and affordably (DWAF, 2003 p. 2).

Using the adapted framework, the next section first outlines the FBSan policy targets, actors and technology considerations and assumptions for urban contexts as per secondary documents before presenting policy-implementation process data and analysing whether the objectives, financial resources, implementers' capability, decision-making, political support and broader situational influences contributed to policy failure. The discussion section then closes with an evaluation of whether municipal implementation is wholly at fault for failure.

\section{RESULTS AND DISCUSSION}

\section{Policy}

\section{Policy targets}

The FBSan objective was to achieve universal free basic sanitation access by 2010 (DWAF, 2003). The target date was later extended when it was evident that South Africa would miss it (DWA, 2012). The new target aligned sanitation timelines with the then informal settlement eradication aim. National policymakers indicated that universal access meant having a sanitation facility in every household and defined basic sanitation as either a physical structure or service package (see Fig. 3).

Regarding facility type, policymakers aimed to eradicate 'black buckets' - the containers used in household pail-based systems, which were the apartheid government's primary means for servicing non-white areas. Considered relics of discriminatory governance (RSA, 1996b)government must create an enabling environment through which all South Africans can access services and support in obtaining those services, but in the end it is individuals who are responsible (RSA, 1996b: 4, policymakers centred the FBSan vision and funding on replacing buckets with either a ventilated pit latrine (VIP) or an equivalent technology per household.

\section{Actor specification}

National policymakers (DWAF, 2001, 2003)2001c: 4 stated that they would be the water and sanitation policymaker and regulator, and their respective national or provincial counterparts were responsible for administering subsidies, developing hygiene plans, assisting with integrated planning and aligning regional policies with state-wide standards. The national government would subsidise the basic infrastructure and off-site O\&M costs for indigent households, and base policy progress and performance on municipal reporting and verification checks.

FBSan beneficiaries would be involved throughout the service chain; and be responsible for on-site O\&M and for servicing costs above basic levels as consumers. Municipal implementers would follow national policies and standards; be responsible for off-site O\&M; and be held accountable for service delivery. The private sector would also contribute to design, construction and financing to assist municipal provision. Civil society would liaise with beneficiaries; assist with project management and monitoring; and hold municipalities accountable, when necessary.

\section{Technical aspects}

While policymakers envisioned a VIP or its equivalent per household, they did not prescribe FBSan technologies or servicing ratios in recognition that policy had to suit a diverse range of conditions, and that implementers needed discretion to progressively realise objectives based on available resources and local conditions (DWAF, 2003)as well as monitor municipal compliance with national policy, norms and standards (DWAF, 2003: 21. National policymakers, however, noted that municipalities and beneficiaries were to agree on technology, and recommended waterborne sewerage for highdensity urban areas.

\section{Policy implementation}

\section{Valid assumptions}

Causal theory is the means by which objectives are achieved (Mazmanian and Sabatier, 1989). The primary theory underpinning sanitation policymaking was that the government had an adequate policy that established the vision, approach and 'detail of how the policies will be implemented in order to achieve the vision and goals' (DWAF, 2003 p. 3). Additionally, policymakers were under the impression that enough resources were allocated to provide limited amounts

\begin{tabular}{|c|c|}
\hline $\begin{array}{l}\text { Basic sanitation facility: The infrastructure } \\
\text { necessary to provide a sanitation facility which is } \\
\text { safe, reliable, private, protected from the weather } \\
\text { and ventilated, keeps smells to the minimum, is } \\
\text { easy to keep clean, minimises the risk of the spread } \\
\text { of sanitation-related diseases by facilitating the } \\
\text { appropriate control of disease carrying flies and } \\
\text { pests, and enables safe and appropriate treatment } \\
\text { and/or removal of human waste and wastewater in } \\
\text { an environmentally sound manner. }\end{array}$ & $\begin{array}{l}\text { Basic sanitation service: The provision } \\
\text { of a basic sanitation facility which is } \\
\text { easily accessible to a household, the } \\
\text { sustainable operation of the facility, } \\
\text { including the safe removal of human } \\
\text { waste and wastewater from the } \\
\text { premises where this is appropriate and } \\
\text { necessary, and the communication of } \\
\text { good sanitation, hygiene and related } \\
\text { practices. }\end{array}$ \\
\hline
\end{tabular}

Figure 3. Department of Water Affairs and Forestry (DWAF, 2003 p. 46) basic sanitation definitions 
of free capital and O\&M services to poor households, and that municipalities could capably administer policy.

In terms of decision-making and participatory processes, national policy indicated that involved actors would work together in a pipeline (i.e. over a series of stages) to improve demand-driven sanitation over time (DWAF, 1994). It was also assumed that involved actors accepted the state's selfhelp approach and servicing policy. For example, national policymakers assumed that municipalities would provide FBSan and beneficiaries would undertake on-site tasks. Lastly, national policymakers presumed it was technically feasible to replace bucket systems.

FBSan implementation in Cape Town's informal settlements has revealed fundamental problems with the causal theories underpinning national policy. The next sections present and discuss data that challenges the causal assumptions underpinning FBSan. Mazmanian and Sabatier (1989) postulated that many policy failures are rooted in unsound causal theories. In Cape Town, flawed assumptions about policy objectives, resources, capacity, support and technical feasibility affected municipal implementation and ultimately contributed to policy failure.

\section{Clear objectives}

Implementers are often faulted for misinterpreting policy guidance. CoCT (2001)or contained the solid contents on-site in tanks ( 20 officials, however, indicated their understanding of legislation and regulations by utilising the basic sanitation definition in planning, and acknowledging their responsibility for providing access as per their financial, environmental and legal situation. Recognising that waterborne services were costly and often infeasible and/or illegal to install in denselystructured settlements situated on occupied land, officials gave residents the following options: either household VIP, a supposedly 'improved' private household black bucket, or communal access to container-based alternatives at approximately 1 toilet per 5 households.

As per policy, CoCT (2010 p. 2) intended for beneficiaries to keep their toilets 'clean and hygienic' as part of a self-help scheme that entailed community management of their 'own' facilities. Officials, however, encountered marked dissent with FBSan implementation -namely due to contestation over what access meant, what was a suitable VIP equivalent and what was to be provided for free. With regards to the access target of a household facility, municipal officials interpreted this as having a toilet near one's home. In contrast, residents and their advocates understood access as being free and safe to enter, as well as functional for use.

There similarly were distinct interpretations of what an acceptable equivalent technology was. VIPs could not be rolledout across Cape Town's informal settlements due to limited physical space and the inability to build structurally sound pits in sandy soils with high water tables. Residents thus could only choose between a household black bucket and a communal container. The municipality argued that their equivalents technically met the FBSan definition, as many households lacked any sanitation facilities, which meant that this was a progressive improvement upon their current circumstances. The officials further argued that national policymakers had not specified a minimum technology requirement or servicing ratio.

Many did not agree, however, with this interpretation. In 2004, national policymakers stated that buckets in any form did not meet the FBSan definition and needed to be replaced
(DWAF, 2004). Policymakers later retracted this policy position and accepted the prolonged use of container-based sanitation in light of the inability to eradicate the bucket system nationwide (DWAF, 2008). But residents rejected what some described as 'glorified buckets', demanding that CoCT provide waterborne sanitation instead. Officials attempted to meet these demands by introducing sewerage where possible. Most settlements, however, could not accommodate conventional sewerage, and failed implementation of alternative sewerage - namely, a vacuum sewer in 2009 (Taing, 2017a) - left many officials reluctant to innovate.

Municipal officials also experienced backlash against their administration of the self-help component of the FBSan policy. Following policy guidance, officials introduced toilets on a communal basis with the expectation that users would manage them as a 'community.' In other words, municipal officials met the FBSan basic facility definition, and made behavioural assumptions about how residents collectively utilised and maintained toilets. Their expectations contrasted with residents' more common treatment of shared facilities. Communal toilets largely operated as freely accessible public toilets, and fell into disrepair due to poor management. Many residents (as well as advocates) thereafter demanded that the municipality provide users with toilet paper and both on- and off-site O\&M. This suggests residents expected free provision of a service, as per the national basic sanitation definitions.

To curb the municipality's high O\&M and replacement costs, as well as meet their servicing obligations, CoCT commenced a janitorial service for most of its communal toilets from 2013. This meant that CoCT went beyond its responsibility of providing FBSan facilities to meet residents' demands and its constitutional servicing obligations. It also indicates that rather than changing behaviours according to policy, municipal officials ultimately implemented a service informed by prevailing residential practices.

Contested understandings of access, acceptable technology and FBSan are significant to note, as the varied interpretations suggest that policy objectives and corresponding directives were unclear and that policymakers' causal theory of having established a clear vision, goals and approach was flawed. Experience also bears to question whether it is technologically possible to improve upon container-based sanitation in densely populated settlements, and whether policy actors unconditionally supported the government's self-help and community-management approaches.

\section{Financial allotment}

Another major policy assumption was that municipalities had sufficient FBSan funds through capital subsidies and O\&M tariffs (DWAF, 2003)as well as monitor municipal compliance with national policy, norms and standards (DWAF, 2003: 21. Municipal officials said that they funded informal settlement infrastructure from local cross-subsidies due to their inability to use housing grants in informal areas. Moreover, they struggled to fully subsidise O\&M given the increasing demands of non-paying consumers in burgeoning informal settlements, and their having to undertake the unbudgeted items to fulfil servicing obligations. Unbudgeted items ranged from providing cleaning services to conflict mediation and hiring private security during servicing disputes. CoCT (2001 p. 11) additionally provided free water and sanitation to all residents due to the challenge of establishing eligibility criteria for indigent households. 
Residents and advocates further indicated the need for resourcing handwashing and drainage infrastructure; electricity within and surrounding facilities; and improved systems for solid waste removal. The unforeseen sanitation expenses and funding demands for the urban poor seem tied to the government's ambitious informal settlement eradication plan, which did not allow for comprehensive long-term support; assumptions of sanitation being apolitical; and general oversight of administrative costs, which was needed for new programming. Learning from the latter, CoCT (2013) officials obtained additional funding from national government when developing its informal settlement janitorial service.

\section{Implementation capability}

Research indicated that several disabling institutional environments affected implementers' ability to service informal settlements. Firstly, policy contradictions complicated service provision. Municipalities are constitutionally compelled to provide all South Africans with access to services, irrespective of land tenancy. CoCT officials hence were obliged to provide sanitation access despite the national government's intention of eradicating all informal settlements by 2014 .

A policy vacuum also stunted servicing efforts. There was a lack of national guidance for informal settlements considering the eradication aim. Additionally, municipal officials noted that FBSan seemed conceived for rural settings, for the endorsed technology (VIPs) and servicing ratio (a toilet per household) was typical of rural homesteads. This household focus resulted in a policy vacuum for communal services in urban areas.

Local partisan politics also affected municipal officials' capability. Cape Town is situated in the only Democratic Alliance (DA) managed province in an African National Congress (ANC) dominated government. The DA has been the ANC's official opposition since 1999. It wrested control of Cape Town in 2006 - which was then the only metropolitan area not governed by the ANC and became the province's ruling party in 2009. Officials, who had trained as engineers, construction managers or plumbers, often complained that partisan politics in government and communities harmed and stalled sanitation delivery. These officials thus said sanitation needed to be driven by technical feasibility rather than politics, which indicates their perception that sanitation servicing should (and can) be apolitical.

Municipal officials said that an ongoing restructuring process additionally stymied their efforts. CoCT had aimed to restructure its organisation and administrative functions as a decentralised but coordinated unicity by January 2003 . This target, however, was optimistic, as officials said that they were 'fatigued' from 'perpetual restructuring' that left the municipality in a transitional state 15 years after its establishment, due to executive turnover.

Municipal officials who tried to develop informal settlement projects noted that they were structurally, institutionally and personally ill-prepared. Officials said they struggled to synchronise service delivery amongst 'silos' due to similar or overlapping departmental mandates. CoCT's failed vacuum sewer, for example, illustrated how successive rounds of municipal restructuring exacerbated extant tensions and rivalries between two departments responsible for informal settlement sanitation services (Taing, 2017a). Officials also said that they could not project necessary informal settlement capital, operation and rehabilitation costs in advance because the municipality operates from preapproved annual budgets.

Finally, informal settlement sanitation interventions tend to contain policy objectives of simultaneously improving conditions while creating temporary job opportunities for residents. Some officials responsible for sanitation provision said they were ill-prepared and technically not responsible for formulating development policy and negotiating timeconsuming local politics. This highlights the dilemma of holding municipal officials accountable or compelling them to undertake responsibilities in multi-objective initiatives that some claimed they were unqualified for or did not feel obliged to implement.

In brief, there are a range of socio-political, institutional and financial constraints that disabled municipal officials' capability to execute policy. These constraints counter the causal theory of FBSan being sufficiently funded for implementation, and that municipalities could administer policy. The next section further elaborates on how decentralisation affected decision-making and participatory pipelines.

\section{Extent of (de)centralisation}

National policymakers had devolved decision-making to (a) municipal officials, who were to decide on appropriate and affordable services; and (b) communities, who would later 'participate in decision-making about what should be done and how' and accept infrastructural responsibility (DWAF, 2001 pp. 21, 11). Many community representatives and advocates, however, objected to the municipality's prioritisation of itself over residents' considerations. They argued that processes needed to be bottom-up, with decisions being made and methods set on a settlement basis. The shortcomings of the community-management scheme further suggested that residents wanted to be consulted about what and how sanitation would be provided, but not necessarily accept responsibility. CoCT thus implemented a janitorial programme in which residents were contracted as cleaners to undertake on-site O\&M. This programme indicated that decision-making for and responsibilities of informal settlement toilets were devolved to the lowest accountable level: the municipality.

Municipal officials' experience indicated that they eventually adapted consultative approaches to satisfy both supporters and opponents. While consensus building is time-consuming, several officials said it was necessary to have the backing of opposing factions because unresolved intra-community tension delayed rollouts and resulted in poor project outcomes. Despite municipal accommodations, critics claimed that officials' mostly representative-based consultation process did not adequately capture the diversity of informal settlement perspectives. They thus demanded further devolvement to allow input from oft-overlooked beneficiaries. Heterogeneous perspectives were also evident within the municipality, as discussed next.

Providing sanitation in a pipeline manner also requires overcoming numerous veto (policy disapproval) and clearance (implementation endorsement) points because support and direction must be obtained from various departments that are responsible for aspects of town engineering and informal settlement development. Officials said it was challenging to obtain support and coordinate these line functions, especially when given contradictory instructions and advice.

Municipal officials implied that their elected counterparts 
or senior managers largely dictated their actions. The author, however, observed that officials had discretion over projectlevel decisions. They nonetheless tended to defer decisionmaking until they received directives or approvals from senior management in order to avoid being held personally and hence financially accountable for 'fruitless and wasteful expenditure,' as per the 1999 Public Finance Management Act (National Treasury, 2014 p. 1). Considering this, municipal officials said compliance with senior management's (often unwritten) directives or prevailing practices were a significant form of civil service protection, as informal settlement servicing tended not to be covered in policy. The data suggests that while the municipality devolved implementation responsibilities to various departments, political and executive leadership tended to set agendas and methods.

This indicates that policy actors had conflicting notions of the extent that decision-making and participatory processes should have been decentralised. While residents and their advocates proposed context-specific processes at an informal settlement level, CoCT opted to retain authority because they were unable to hold residents accountable. Municipal officials additionally struggled with the inherent conflict between CoCT's decentralised structure and centralised decisionmaking system. These various constraints suggest that the causal theory of sanitation actors working together in a pipeline manner is difficult, considering competing priorities and perspectives.

\section{Political support}

As with many public projects, political support is a key variable that affects successful or failed implementation outcomes. Amongst public officials, it was clear that national legislative and regulatory authority significantly influenced municipal design, as municipal officials applied state policy and the self-help approach in sanitation programming. Infrastructure dysfunction throughout informal settlements, however, prompted CoCT to identify a new policy and approach that improved service reliability. Municipal officials' successful introduction of a janitorial service with support from national policymakers indicates that political support from those with legislative, regulatory and financial authority is instrumental in transforming services. In contrast, municipal ability to disregard highly critical recommendations from the South African Human Rights Council (SAHRC, 2014) indicates that the public watchdog lacks both legislative and regulatory authority to enforce change.

The public also played a significant role in policy change. Because of the open toilets scandal, sanitation became a regular fixture in South African media, instigating public interest and support for universal access. Officials subsequently received additional resources to scale-up operations (e.g. a janitorial service in 2013). Sanitation being at the fore of public consciousness also provoked reform and action at a national level, for toilet scandals throughout the country prompted restructuring within government institutions (DHS, 2010) and the launching of a state-wide investigation (MSTT, 2012). These points suggest that public support can affect resource allocation, institutional reform and government agendas.

There were several constituency groups at the residential level that further demonstrated they had an important footprint. FBSan beneficiaries' actions, for instance, greatly affected service provision. Both national and municipal officials had initially presumed that all actors accepted the self-help policy. The fallibility of the community-managed toilet system, however, indicated to the municipality that it was imprudent to expect households in sprawling settlements to use and manage toilets collectively. The janitorial service suggests that residents' prevailing practice and advocacy motivated municipal policy reformulation.

Municipal officials considered 'buy-in' in communities critical to achieving success in sanitation projects. Representative support amongst community leadership was especially significant despite their occasional observances of self-enrichment, nepotism and cronyism, as it facilitated implementation. Getting paid contributed to the temporarily employed workers' support for janitorial services, though some noted their dissatisfaction with not having longer-term employment.

Lastly, as national policymakers had intended, advocacy groups held local government accountable. For example, social advocates criticised CoCT's janitorial service operational policy, which they said contained 'permissive language' and no criteria (e.g. timelines or methods) to hold the municipality accountable. Advocates, however, had limited effect on municipal processes and systems, because CoCT either aligned its resources with groups that supported its methods, or adopted an adversarial relationship with those that publicised dissent.

These impacts indicate a diverse range of viewpoints and interests in sanitation servicing that have affected municipal implementation. Situational influences next discuss links between informal settlement development and faults in the technological assumption underpinning the FBSan objective.

\section{Situational influences}

The acceptance of informal settlements being 'here to stay' was critical in changing anti-servicing municipal attitudes and mindsets. The decision to increase sanitation coverage, however, was not always welcomed by residents who wanted housing or job security. An official, for example, said that, 'It was shit going to the communities, and fiddling with some toilets when you knew that wasn't the problem.' This highlights the difficulty of separating sanitation delivery from the broader socio-political context.

Another significant factor is technological feasibility. To date, a technology that improves upon buckets has yet to be identified, and the preferred option (conventional sewerage) is not always possible to retroactively install. Introducing alternative sewerage is logical, but its management necessitates additional capacity in an already overstretched administration that is reluctant to test new technologies. These problems illustrate that while technology choice is important, the aforesaid policy-implementation variables that inform delivery and management play a far more significant role in informal settlements sanitation. The impact of the policyimplementation process variables is discussed further in the next section.

\section{Policy evaluation}

\section{Actors' synergy}

Two worldviews underpinned Cape Town's sanitation debate. The first focused on redressing historical wrongs according to the lived reality of informal settlement users. 
Policy beneficiaries, their advocates and the SAHRC adopted this bottom-up perspective. Municipal officials argued that implementation realities have first to be addressed-especially considering their constitutional obligation to realise sanitation rights, thus indicating a bottom-up approach starting at government's lowest level.

Additionally, policy actors' interaction and subsequent disputes exposed clashing understandings of why sanitation policy is formulated and how it should be applied. National policymakers adopted a pluralistic stance, in which former DWAF Director-General Mike Muller (pers. comm., 21 April 2015) explained aspirational policies needed to be 'broad enough to cover all situations that might occur within it.' Like national policymakers, Cape Town officials also produced aspirational policies, though their documents were practically written to attain funding for foreseen implementation tasks and often based on prevailing practices. Officials also established operational policies, though much of this was unwritten, in part to flexibly accommodate for unforeseen responsibilities.

Outspoken residents and their advocates, however, tended to view policy as being populist, and hence often demanded that the government adapt top-down policies and processes to accommodate bottom-up perspectives. Social advocates, as well as the SAHRC, additionally understood policy as prescribed rules that could be used as regulatory tools. The former hence preferred precise phrasing to aspirational language, which was difficult to enforce.

In hindsight, the policy actors participated in Cape Town's sanitation policy process in various capacities. As leading policymakers and regulators, national policymakers set agendas, formulated policy and financed strategies that influenced the design of municipal processes and the provision of new infrastructure. Their regulatory impact to date, however, has been minimal. Due to national policy shortcomings, municipal officials developed sanitation policies as per their requirements. CoCT thus adopted multiple policy roles - as an agenda-setter, formulator, decision-maker, implementer and regulator.

FBSan beneficiaries influenced sanitation provision by not fulfilling their intended roles in community-managed toilet schemes. They also influentially set agendas and affected implementation by communicating dissatisfaction through government platforms or protests. Civil society groups also were agenda-setters and evaluators in the sanitation debate. Their criticisms resulted in adapted participatory processes and greater municipal transparency. The policy actor with minimal impact, however, was the SAHRC, which lacked legislative or regulatory authority over the municipality. The last section summarises the policy outcomes and offers suggestions for revision based on the findings from the discussion.

\section{Policy outcomes}

In August 2013, national policymakers announced that they had to amend unintended policy gaps - such as a disjointed economic regulatory framework (DWA, 2013). Helgard Muller (pers. comm., 22 April 2015), a former senior policymaker in national government, further noted that the Executive Cabinet had never formally approved a draft FBS policy that specified the manner that services were to be provided and how FBSan was thus to be implemented. Part of the reasons for not having regulatory functions established after 2 decades was the ongoing debate of whether it should be conducted by the national policymaker or an independent institution (Camay and Gordon, 2005); the ongoing shuffle of sanitation duties between 4 national entities from 2008 to 2014; and the need to make 'significant' legislative amendments before developing regulations (DWA, 2013 p. 17).

These points suggest that there were significant sanitation-specific regulatory gaps in addition to the informal settlement and shared sanitation policy vacuum. CoCT hence implemented the FBSan policy with limited direction and critical oversight from its national counterparts.

National policymakers also notably did not provide criteria for measuring what are accessible, safe and appropriate basic sanitation facilities or shared services. Of course, as Mike Muller (pers. comm., 21 April 2015) pointed out, the definition cannot comprehensively address every aspect of sanitation delivery. For instance, Muller noted that the basic standard 'doesn't deal with security of using a facility outside a house in the middle of the night,' but 'if it did, the sanitation policy would morph into a security policy.' He thus posited whether 'the broad definition is adequate' considering implementation requirements?

Conflicts amongst Cape Town policy actors suggest that national policymakers' blanket definition was inadequate for implementation. A review by policymakers previously indicated that municipalities across the country struggled with 'vague' policy language, such as what precisely constitutes access (DWA, 2012: 11). Implementation theorist Matland (1995) previously noted that vague standards and mandates without specific goals and indicators to measure outcomes often resulted in general societal norms and values being used as policy's evaluative criteria. Instead of explicit policy language and benchmarks, the Cape Town example indicates that local actor's norms and values were important FBSan evaluative criteria for informal settlements, as prevailing practice ultimately dominated formal policy

Additionally, CoCT officials could not follow national policy as it was designed. The policy based on rural contexts proved inappropriate for informal settlements, as natural and built environment constraints largely precluded anything but shared services. Policy beneficiaries and advocates have largely rejected the top-down approach underpinning the decade-long municipal implementation of households being responsible for community toilets. The municipality consequently shifted responsibility for shared toilets from private households to public officials.

Residents' practices and advocates' conflicts with municipal officials highlighted that the FBSan vision and definition was unclear. While the national and municipal governments intended to provide free infrastructure to the poor, residents' actions and demands indicate that they expected and desired free O\&M as well. This suggests that the lack of definition for what exactly was 'free' complicated provision.

Considering these shortcomings, CoCT municipality effectively became the preeminent sanitation policymaker and regulator in its jurisdiction and developed a policy that flouted a significant aspect of national policy. The municipality's departure from national policy was to accommodate its implementation realities with residents' lived realities. This outcome suggests that local actors and factors can and have significantly affected the formulation of sanitation policy.

\section{Policy revision}

South Africa has made massive strides in establishing a rightsbased sanitation policy from scratch in its first 20 years of rule, but universal access has yet to be achieved. National policymakers have recognised that the government requires 
'one streamlined' policy to address implementation and regulatory challenges (DWA, 2013 p. 24). The then Minister of Water and Sanitation has, moreover, expressed a need to revise norms and standards (Mokonyane, 2015). To get closer to servicing goals, policy actors should consider using findings from implementation research to inform revision. For instance, the following recommendations based on the application of an implementation studies framework offers practical advice on how to revise the sector's approach, framework and standard according to municipal experiences.

\section{Multi-level governance and multidisciplinary approach}

This research indicates the need to incorporate knowledge of lived and implementation realities when reformulating policy, as the present viewpoint of turning national policy into municipal practice ignores the influence and impact local actors have in policymaking and service delivery. Understanding and addressing the diverse actors involved in multi-level governance is necessary to design a workable universal access policy for highly contested areas such as informal settlements.

Similar to water resources management (Funke et al., 2014), professionals with science backgrounds have been tasked with tackling South Africa's sanitation problem. While their expertise is needed, they seem reluctant to accept the politics inextricably tied to the practical and lived realities of service delivery. To claim that sanitation is apolitical ignores reality, for it cannot be separated from the politics that often drive servicing. Basing provision solely upon technical feasibility also resulted in services that beneficiaries and advocates reject as being technology-driven, top-down and undemocratic. Given that sanitation is a crosscutting concern that a multitude of interest groups are concerned with, a multi-disciplinary approach is needed whereby actors representing various backgrounds and perspectives develop policy together to tackle differences in worldview, motives and approaches that have emerged in the democracy's second decade.

\section{$\underline{\text { Holistic and inclusive sanitation framework }}$}

The findings on implementation highlight Mehta and Mehta's (2013) argument for shifting urban sanitation 'beyond the household level facilities to encompass wider dimensions of equity, public health and national environment' through citywide approaches. Such a shift should holistically address sanitation by integrating the provision, collection, disposal and reuse of all domestic water and waste (human and animal faeces and urine, greywater and rubbish) and stormwater. Given South Africa's water security concerns, it is also significant to tie urban sanitation planning to water resources and demand management.

Global sanitation experts have highlighted city-level approaches as the best way to achieve inclusive service delivery (BMGF et al., 2017). Adopting a holistic and inclusive framing is relevant to South African municipalities, as they are increasingly tasked with broadening sanitation beyond the provision of a toilet.

\section{Free basic sanitation standard criteria clarification}

South Africa's sanitation sector focuses on the adoption, implantation and enforcement of laws and policies that are consistent with national policy. There hence is an expectation that implementers and beneficiaries should subscribe and comply with policymakers' rules and methods. This legalistic approach is pluralistic and prescriptive and has resulted in little consideration of practical guidance for providing or using free services. A former municipal manager of Durban's water services explained,

What is often overlooked is what does the "right" really mean in practical terms - how much, what quality, how

often, how far, how safe to access? (Neil McLeod, as cited by Muller, 2011 p. 7).

Put differently, policy actors need to clarify the criteria of the broadly framed FBSan standard, by establishing what precisely is to be provided at no cost and offer definitions and means to assess what is safe, reliable, private, accessible, sustainable and appropriate. National policymakers, for instance, have a free water allowance of $6 \mathrm{~kL}$ per household, and explicitly defined basic water supply as infrastructure that supplies a stipulated quantity (25 L per person per day); at a specific distance ( $200 \mathrm{~m}$ from a household); and at a particular rate (minimum flow of $10 \mathrm{~L}$ per minute for communal taps) (DWAF, 2003: 46). While the sanitation standard need not be quantifiable, there should be a means for measuring it for implementation and regulatory purposes.

\section{CONCLUSIONS}

South Africa's democracy has been lauded worldwide for its transformative policies and legal frameworks that have boldly redressed historical discrimination. The government has made massive strides in establishing a comprehensive sanitation policy in its first decade of democratic rule. The ambitious objectives, however, have yet to be realised, for many South Africans lack access to toilets reserved exclusively for their households. The popular response for this failure is to hold local government accountable for not following national policy and regulations.

This focus of realising prescriptive rights-based policy misses how implementers and beneficiaries' prevailing practices can affect policy realisation and overlooks policy gaps. This paper hence puts forward a need to adapt policymaking in South Africa to include implementation framing, by accounting for contestation in policy processes; reformulating policy to reflect lived and implementation realities; and working both inside and outside of government to clarify ambiguous policy and close regulatory gaps.

While research is available on FBW, South Africa's FBSan has yet to be critically studied. This paper valuably contributes research on this topic. It uses a multivariate policy implementation framework to analyse a controversial sanitation policy that is regarded as a keystone of progress in post-apartheid South Africa. The paper brings a unique view to discussions, as it contrasts the dominant framing of transforming national policy into local practice. Accepting that policy processes do not unfold in sequential stages and that policy is not just made by national policymakers is critical to reformulate aspirational policies according to micro-level needs, politics and actions.

Similarly, there is a legalistic sector bias for achieving water and sanitation rights at a global scale. As Singh (2013) indicated, research and interventions addressing the interface of local implementation and socio-cultural contexts can advance discussions beyond this narrow purview. Further research on and reflections of systemic conditions are needed, as Castro and Heller (2012) stated, to improve decision-making, organisation, financing and governance concerning the planning and management of basic services. 


\section{ACKNOWLEDGEMENTS}

The research data stems from studies funded by the WRC (K5/1827 and K5/2120). The author received funding from the European Union's Seventh Framework Programme (grant agreement no 606838) to write-up the research, with additional support from IHE Delft and UNU-INWEH. This research would not have been possible without contributions from the University of Cape Town's Urban Water Management Research Unit and the participation of residents from informal settlements, and CoCT officials and SJC advocates working towards change. Mike Muller and Helgard Muller also provided valuable insight into policy development, and the anonymous reviewers' comments strengthened this paper.

\section{REFERENCES}

BMGF, EMORY UNIVERSITY, PLAN INTERNATIONAL, UNIVERSITY OF LEEDS, WATERAID and WORLD BANK (2017) Citywide inclusive sanitation. World Bank, Washington, D.C.

CAMAY P and GORDON A (2005) Poverty Reduction through Improved Regulation. The Co-operative for Research and Education, Johannesburg.

CASTRO JE and HELLER L (2012) Water and Sanitation Services: Public Policy and Management. Earthscan, London. 363 pp.

COCT (City of Cape Town) (2001) Water Services Development Plan. City of Cape Town, Cape Town.

COCT (City of Cape Town) (2013) Implementation of the Expanded Public Works Programme (EPWP). City of Cape Town, Cape Town.

DELEON P (1999) The missing link revisited: contemporary implementation research. Polic. Stud. Rev. 16 (3/4) 312-338. https:// doi.org/10.1111/j.1541-1338.1999.tb00887.x

DHS (Department of Human Settlements, South Africa) (2004) Breaking New Ground: A comprehensive plan for the development of sustainable human settlements. Department of Human Settlements, Pretoria.

DHS (Department of Human Settlements, South Africa) (2010) Annual report for the year ended 31 March 2010. Department of Human Settlements, Pretoria.

DHS (Department of Human Settlements, South Africa) (2012) Human Settlements Portfolio Committee briefed on sanitation task team report (Media Statement, 14 September 2012). Department of Human Settlements, Pretoria.

DPLG (Department of Provincial and Local Government, South Africa) (2007) Policy process on the system of Provincial \& Local Government. Department of Provincial and Local Government, Pretoria.

DWA (Department of Water Affairs, South Africa) (2012) Report on the Status of sanitation services in South Africa. Department of Water Affairs, Pretoria.

DWA (Department of Water Affairs, South Africa) (2013) National Water Policy Review: Water Policy Positions. Department of Water Affairs, Pretoria.

DWAF (Department of Water Affairs and Forestry, South Africa) (1994) Water Supply and Sanitation Policy White Paper. Department of Water Affairs and Forestry, Pretoria.

DWAF Department of Water Affairs and Forestry, South Africa (2001) White Paper on Basic Household Sanitation. Department of Water Affairs and Forestry, Pretoria.

DWAF Department of Water Affairs and Forestry, South Africa (2003) Strategic Framework for Water Services. Department of Water Affairs and Forestry, Pretoria.

DWAF Department of Water Affairs and Forestry, South Africa (2004) National Sanitation Strategy. Department of Water Affairs and Forestry, Pretoria.

DWAF Department of Water Affairs and Forestry, South Africa (2008) Free Basic Sanitation Implementation Strategy. Department of Water Affairs and Forestry, Pretoria.
FUNKE N, MEISSNER R, NIENABER S, and NTOMBELA C. (2014) What does research have to say about South Africa's water institutions? The Water Wheel [13 (1) 32-34]. Water Research Commission, Pretoria.

HILL M and HUPE P (2010) Implementing Public Policy. SAGE Publications, London.

HUCHZERMEYER M (2001) Housing for the poor? Negotiated housing policy in South Africa. Habitat Int. 25 (3) 303-331. https:// doi.org/10.1016/S0197-3975(00)00037-0

KASRILS R (2001) The value and price of water (The women of Lutsheko). Water Sci. Technol. 43 (4) 51-55. https://doi.org/10.2166/ wst. 2001.0176

LASSWELL HD (1956) The Decision Process: Seven Categories of Functional Analysis. University of Maryland, College Park.

MATLAND RE (1995) Synthesizing the implementation literature: the ambiguity-conflict model of policy implementation. J. Public Admin. Res. Theory 5 (2) 145-174.

MAZMANIAN DA and SABATIER PA (1989) Implementation and Public Policy, with a New Postscript. University Press of America, London. 346 pp.

MEHTA M and MEHTA D (2013) City sanitation ladder: moving from household to citywide sanitation assessment. J. Water, Sanit. Hyg. Dev. 3 (4) 481-488. https://doi.org/10.2166/washdev.2013.134

MJOLI N, SYKES G and JOOSTE T (2009) Towards the realization of free basic sanitation. WRC Report No. TT 422/09. Water Research Commission, Pretoria.

MOKONYANE N (2015) Minister of Water and Sanitation Budget Speech (21 March). URL: https://pmg.org.za/briefing/20924/

MOSDELL T (2006) Free Basic Services: The evolution and impact of Free Basic Water policy in South Africa. In: Pillay U, Tomlinson R and Du Toit J (eds) Democracy and Delivery: Urban Policy in South Africa. Human Sciences Research Council, Cape Town.

MSTT (Ministerial Sanitation Task Team) (2012) Ministerial Sanitation Task Team Report. Human Settlements Department, Pretoria.

MULLER H (2011) The Right to Water and Sanitation - the South African experience. In: Proceedings of Consultation with State Actors: Good Practices in Water, Sanitation and Human Rights, 20-21 January, Geneva, 2011.

MULLER H (2015) Personal communication, 22 April 2015. Helgard Muller, former DWAF Chief Director: Water Services, independent water and sanitation consultant, Pretoria, South Africa, Gauteng, South Africa.

MULLER M (2008) Free basic water - a sustainable instrument for a sustainable future in South Africa. Environ. Urbanization 20 (1) 67-87. https://doi.org/10.1177/0956247808089149

MULLER M (2015) Personal communication, 21 April 2015. Prof. Mike Muller, former DWAF Director-General, Adjunct Professor, University of Witwatersrand Graduate School of Governance, Johannesburg, South Africa], Former DWAF Director-General, Gauteng, South Africa.

NATIONAL TREASURY (2014) Guideline on Fruitless and Wasteful Expenditure. National Treasury, Pretoria.

RSA (Republic of South Africa) (1996a) Constitution of the Republic of South Africa (Act No. 108 of 1996). Government Gazette 17678. Republic of South Africa, Pretoria.

RSA (Republic of South Africa) (1996b) National Sanitation Policy White Paper. National Sanitation Task Team, Pretoria.

RSA (Republic of South Africa) (1997) Water Services Act (Act No. 108 of 1997). Government Gazette 18522. Republic of South Africa, Pretoria.

RSA (Republic of South Africa) (1998) Municipal Structures Act. (Act No. 117 of 1998). Government Gazette 19614. Republic of South Africa, Pretoria.

RSA (Republic of South Africa) (2000) Municipal Systems Act. (Act No. 32 of 2000). Government Gazette 21776. Republic of South Africa, Pretoria.

SABATIER PA (1986) Top-down and bottom-up approaches to implementation research. J. Public Polic. 6 (1) 21-48. https://doi. org/10.1017/S0143814X00003846

SABATIER PA (2007) Theories of the Policy Process. Westview Press, Boulder. 
SAHRC (South African Human Rights Commission) (2014) Social Justice Coalition \& City of Cape Town (WC/1314/0095). South African Human Rights Commission, Johannesburg.

SINGH N (2013) Translating human right to water and sanitation into reality: a practical framework for analysis. Water Polic. 15 (6) 943-960. https://doi.org/10.2166/wp.2013.020

SJC (Social Justice Coalition) (2013) Janitorial services: SJC submits final letter of demand to Cape Town (12 July). Social Justice Coalition, Cape Town.

STATS SA (2001) Census in brief. Statistics South Africa, Pretoria.

TAING L (2017a) How socio-political factors affected the implementation of Cape Town's vacuum sewer. Environ. Sci.: Water Res. Technol. 3 (3) 513-519. https://doi.org/10.1039/C6EW00089D
TAING L (2017b) Informal settlement janitorial services: implementation of a municipal job creation initiative in Cape Town, South Africa. Environ. Urbanization 6 1-16. https://doi. org/10.1177/0956247816684420

TAING L, ARMITAGE NP, ASHIPALA N and SPIEGEL AD (2013) TIPS for sewering informal settlements: Technology, Institutions, People and Services. WRC Report No. TT 557/13. Water Research Commission, Pretoria.

TAING L, SPIEGEL A, VICE K and SCHROEDER M (2014) Free basic sanitation in informal settlements. Water Research Commission, Pretoria.

WILKINSON P (1998) Housing policy in South Africa. Habitat Int. 22 (3) 215-229. https://doi.org/10.1016/S0197-3975(98)00001-0 